\title{
PerCursos
}

\section{Espelho, espelho meu... a ferida narcísica de um colonialismo falocêntrico}

\section{Resumo}

O que aconteceria se nossos corpos falassem, se nossas bocas amordaçadas gritassem o silêncio de todos esses séculos? Grada Kilomba, em A memória da plantação, nos expõe que, através da criação de uma nova linguagem decolonial, é possível a reconstrução das estruturas de poder e que as identidades marginalizadas podem, então, reconfigurar a noção de conhecimento. Sabemos que o sistema patriarcal moderno colonizou ao longo da história nossas narrativas, nossas línguas, que são intraduzíveis para os colonizadores, sendo a língua um ideal regulatório. bell hooks, em $E$ eu não sou uma mulher?, descreve como a literatura foi eficaz na criação de um imaginário dos corpos negros. Lugones nos fala como o processo moderno colonial de gênero aprisiona os corpos latino-americanos, ou mesmo, como Lélia Gonzalez chama, amerifricanos. A partir dessas vozes e do pensamento feminista decolonial, defendo a urgência que temos em criar uma nova linguagem fugindo das restrições gramaticais que perpassam o gênero, a sexualidade e racialidade, sendo essas categorias imbricadas. É preciso tomar uma posição de autores e não de objetos, narrar nossa própria história, dando lugar a um outro vocabulário, delatando nossos silêncios, nossas máscaras de mordaças colonizadoras, nossas vozes torturadas, nossas línguas rompidas, idiomas impostos, discursos impedidos. Escrever é, portanto, um ato de resistência e uma fome coletiva e política de ganhar voz. Proponho um trabalho que é, ao mesmo tempo, um discurso político e uma narrativa pessoal e poética, que coloque a precariedade, a dor, a emoção, as experiências dos corpos amerifricanos incorporados no discurso e que rompa com a lógica colonial moderna capitalista, e que também é patriarcal.

Palavras-chave: Feminismo. Decolonial. Gênero. Racismo.

\author{
Aline de Oliveira Rosa \\ Doutorando em filosofia pela \\ Universidade Federal do Rio de \\ Janeiro - UFRJ. \\ Pesquisadora do Grupo de \\ Pesquisa Descolonial Carolina \\ Maria de Jesus, vinculado ao \\ Laboratório Antígona de Filosofia \\ e Gênero - UFRJ. \\ Brasil \\ alinerosamoreira@hotmail.com
}

\footnotetext{
Para citar este artigo:

ROSA, Aline de Oliveira. Espelho, espelho meu... a ferida narcísica de um colonialismo falocêntrico.

PerCursos, Florianópolis, v. 22, n.48, p. 61 - 82, jan./abr. 2021.
}

\section{DOI: $10.5965 / 1984724622482021061$}

http://dx.doi.org/10.5965/1984724622482021061 


\title{
Mirror mirror mirror ... the narcissistic wound of phallocentric colonialism
}

\begin{abstract}
What would happen if our bodies spoke, if our gagged mouths screamed the silence of all those centuries? Grada Kilomba in The memory of the plantation shows us that through the creation of a new decolonial language it is possible to reconstruct the structures of power and that marginalized identities can then reconfigure the notion of knowledge. We know that the modern patriarchal system has historically colonized our narratives, our languages, which are untranslatable to colonizers, with language being a regulatory ideal. bell hooks on And I'm not a woman? describes how the literature was effective in creating an imaginary of black bodies. Lugones tells us how the modern colonial gender process imprisons Latin American bodies, or even, as Lélia Gonzalez calls it, Amerifricans. Based on these voices and decolonial feminist thinking, I defend the urgency that we have to create a new language, escaping the grammatical restrictions that pervade gender, sexuality and raciality, these categories being interwoven. It is necessary to take a position of authors and not of objects, to narrate our own history, giving way to another vocabulary, denouncing our silences, our colonizing gags masks, our tortured voices, our broken languages, imposed languages, im-peded speeches. Writing is, therefore, an act of resistance and a collective and political hun-ger to gain a voice. I propose a work that is both a political discourse and a personal and poetic narrative, which places the precariousness, the pain, the emotion, the experiences of the Amerifrican corporations incorporated in the discourse and which breaks with the mod-ern capitalist colonial logic, and which also patriarchal.
\end{abstract}

Keywords: Feminism. Decolonial. Gender. Racism. 


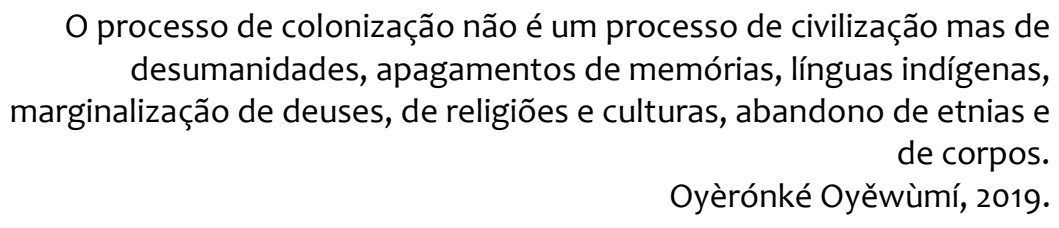

\section{Introdução}

O patriarcado é uma estrutura de poder social centralizada no homem e/ou no masculino, um sistema hegemônico em que o homem mantém o poder primário e predominante nas funções de lideranças políticas, econômicas, como autoridade moral, de privilégios sociais e com o controle das propriedades, bem como o domínio da família e a hierarquia sobre as mulheres e/ou feminino. É o patriarcado um alicerce da sociedade moderna, modelo de civilização presente ainda hoje como uma ferida colonial.

Somos colonizados por esse ideal de homem moderno, este regula a vida, a economia, o trabalho, o Estado e a política, o que Aníbal Quijano chama de "colonialidade do poder" (QUIJANO, 2001, p. 5), um padrão capitalista eurocêntrico e global que tem como marco a regulação da produção do conhecimento, uma epistemologia universal do que é bom e verdadeiro, esta é a "colonialidade do saber" (QUIJANO, 2001, p. 5). Esses dois eixos ordenam as disputas de controle de todas as áreas da vida, de tal maneira que o significado e as formas de dominação em cada uma delas são inteiramente atravessados pelo conceito de modernidade. Assim como também a regulação dos corpos exercida pela heteronormatividade e a imposição do binarismo de gênero são formas da violência colonial, um instrumento de ação do colonialismo que possui dentre de um de seus mecanismos, a separação categorial.

O pensamento decolonial surge como parte da resistência histórica e coletiva de corpos que resistem a esse modelo, pensando a decolonialidade como motor que nos impulsiona a reaprender a ver e ouvir, para que possamos enxergar novos caminhos que não sejam através das lentes do mundo ocidental, que por anos vem negando nossas culturas, nossos saberes e nossas línguas. Resgatando a "Abya Yala”, que na língua do povo Kuna significa "terra madura", "terra viva" ou "terra em florescimento", o movimento decolonial, e sobretudo feminista, propõe um resgate do nosso lugar na 
modernidade, da liberdade dos corpos latinos, das nossas línguas e do nosso território epistemológico, da memória e de nossas histórias.

O feminismo decolonial ${ }^{1}$ é um movimento de insurgência coletiva que rompe com o pensamento liberal individualista, acreditando na força que tem a construção de laços comunitários, no compartilhamento de experiências, de estar entre diferentes, na multiplicidade e no reconhecimento de outrxs. A resistência à colonialidade/modernidade implica: um movimento antirracista, anticapitalista, anti-imperialista; a revisão dos métodos epistemológicos, da língua colonizada, e diria também, das traduções, como aponta Grada Kilomba (2019) para o problema da tradução do termo gênero e também Cusicanqui (2018), ao apontar uma fuga da língua opressora colonial.

É evidente que padrões e estéticas coloniais representam hoje um modelo que prevalece de forma violenta: a masculinidade sobre a feminilidade. E que caracteriza um patriarcado de alta intensidade na dominação das relações e privilégios do homem sobre a mulher e sobre corpos afeminados. E que, diante desse modelo, os corpos diferentes as minorias diante do majoritário homem-branco-cristão-europeu -, o corpo LGBTQIA+, a

\footnotetext{
1 Utilizo o termo decolonialidade a partir de Luciana Ballestrin: "a expressão "decolonial” não pode ser confundida com "descolonização". Em termos históricos e temporais, esta última indica uma superação do colonialismo; por seu turno, a ideia de decolonialidade indica exatamente o contrário e procura transcender a colonialidade, a face obscura da modernidade, que permanece operando ainda nos dias de hoje em um padrão mundial de poder. Trata-se de uma elaboração cunhada pelo grupo Modernidade/Colonialidade nos anos 2000 e que pretende inserir a América Latina de uma forma mais radical e posicionada no debate pós-colonial. [... ] Defendo a "opção decolonial" - epistêmica, teórica e política - para compreender e atuar no mundo, marcado pela permanência da colonialidade global nos diferentes níveis da vida pessoal e coletiva." (BALLESTRIN, 2013, p. 11). Entendendo que escolher usar a nomenclatura decolonial não é uma decisão apenas no âmbito semântico, mas que é antes de tudo uma ação política, transgressora às marcas deixadas por um sistema opressor colonial ainda vigente. $\mathrm{O}$ argumento de que a palavra decolonial não existe na língua portuguesa não é suficiente para essa escolha, no sentido de que palavras são inventadas o tempo todo; a filosofia o faz, os poetas, a literatura, as feministas decoloniais, com a proposta do surgimento de novas línguas, novas formas de falar e escrever... Isso só mostra que a semântica tem uma natureza política, assim como toda produção de conhecimento. Ainda, ao se tratar do português, uma língua colonizada, decolonial é mais do que uma escolha semântica e gramatical de aproximação ou não aproximação da língua - e, segundo esse argumento, seria mais apropriada a escolha pelo termo descolonial, como sugere algumas autoras -, no entanto, o uso do termo decolonial é o oposto disso, se remete a um termo criado, mais rebelde e desobediente a uma língua colonizada, acreditando ser possível reinventar palavras a partir da emergência plural de nossas experiências, entendendo a língua como não fixa e não normatizadora, assim como Lélia Gonzalez chama o português de "pretuguês" a partir das influências das línguas africanas no sotaque das favelas cariocas (GONZALES, 1984, p. 235). O uso do termo decolonial aponta para uma nova metodologia na luta anti-imperialista e anti-racista, um enfrentamento ao sistema moderno eurocêntrico e suas opressões políticas, econômicas, epistemológicas, de gênero e sexualidade.
} 
mulher negra, os corpos não brancos, os não binários, são inferiorizados e marginalizados.

A partir da proposta apresentada pelo feminismo decolonial, proponho uma reflexão sobre as intersecções gênero-sexualidade-raça a partir da ótica de um feminismo não binário e que rompe com as categorias e unidades universais, visto que essas categorias são resultantes de um sistema moderno colonial e que se traduz num padrão de poder capitalista eurocêntrico patriarcal e global. Dessa forma, parto das seguintes questões: É possível haver relações que não sejam pautadas no modelo moderno colonial de gênero? Como pensar um feminismo anti-patriarcal que crie ações de resistências ao modelo moderno/colonial branco europeu? Como imaginar formas cotidianas de interações que possam ser de resistência à diferença colonial?

\section{A binariedade de gênero: um modelo moderno colonial}

A dicotomia humano/não humano é sem dúvida a chave para entendermos a "ferida colonial" (GONZALEZ, 1984, p. 239) e a manutenção do patriarcado como estrutura de poder, ou seja, o reconhecimento do homem-branco-europeu como aquele que é evoluído e civilizado e de seu oposto, não mulher/homem-não-branca(o)-nãoeuropeia(o) como inferior, subalterna(o), animalizada(o) e não humano.

Lélia Gonzalez aponta que nossa sociedade carrega uma ferida não analisada, não discutida e que se transmite em um racismo estrutural e generificado. Essa estrutura ocorre no inconsciente dos brasileiros, uma sociedade que carrega traços patriarcais e europeus, que se mantêm pela introjeção de um ideal civilizador e que culmina num “orgulho besta de dizer que a gente é uma democracia racial. Só que quando a negrada diz que não é, caem de pau em cima da gente, xingando a gente de racista. Contraditório, né?" (GONZALEZ, 1984, p. 239). Mas é preciso mesmo, como diz Lélia, por o dedo na ferida. "E logo pinta a pergunta. Como é que pode? Que inversão é essa? Que subversão é essa? A dialética do Senhor e do Escravo dá prá explicar o barato" (GONZALEZ, 1984, p. 239). 
Nosso desafio é: como essa dinâmica, que faz parte da psique brasileira², pode ser repensada para fora da colonialidade, para fora da ferida colonial? Penso que uma das práticas para a formação de uma nova psique brasileira, que fuja da normatividade colonial e opressora, é a produção de narrativas orais e saberes sobre nossos povos, nossa cultura, de literaturas não hegemônicas, e também da ocupação dos meios acadêmicos por mulheres não brancas e por corpos que fujam à lógica binária de gênero. A ocupação desses espaços é parte da formação de novas narrativas que, assim, rompem com a ideia de que o homem branco é a figura do saber e do universal. Por isso, proponho uma reflexão sobre nossas práticas, pensando um feminismo da experiência, que considere nossas histórias encarnadas e nossas escritas como uma ação de resistência.

A dicotomia entre aqueles que possuem o direito geopolítico de enunciação epistemológica e aqueles que não são porta-vozes de seu próprio discurso - os silenciados, subalternizados -, ou seja, aqueles que surgem da exterioridade, o "outro", o fora, que não pertence ao conjunto “nós", está presente no discurso da modernidade/colonialidade. Sobre esse assunto, Mignolo afirma:

A exterioridade é o lugar de residência daquela população mundial que não pertence a casa da civilização e da democracia. Assim, a modernidade é um discurso que define a sua interioridade ao criar a diferença a ser marginalizada e eliminada. A retórica da modernidade tem um vocabulário abundante para marcar a diferença, para criar exterioridade espacial e temporalmente: pagãos, bárbaros, primitivos,

\footnotetext{
${ }^{2}$ Aqui me refiro a partir do olhar de Lélia Gonzalez sobre a psique e cultura brasileira e seu racismo e que, consequentemente, culmina em uma neurose nacional. Como Gonzalez (1984), sagazmente aponta, há algo de marcadamente velado, essencialista e naturalizado na hierarquia racial brasileira - que não é sentida como tal e nem mesmo afirmada e reconhecida - que nos leva a uma aparente igualdade de direitos e espaços. Em outras palavras, segundo essa lógica, os lugares são determinados de acordo com os merecimentos, os atributos naturais e essenciais de cada grupo, de forma meritocrata. Assim, "a democracia racial oculta algo para além daquilo que mostra" (GONZALEZ, 1984, p. 30). Ao abordar a questão racial e falar sobre a psique da sociedade brasileira, Lélia considera que "o racismo se constitui como a sintomática que caracteriza a neurose cultural brasileira" (GONZALEZ, 1984, p. 25) e, como todo bom neurótico, "constrói modos de ocultamento do sintoma, porque isso lhe traz certos benefícios" (GONZALEZ, 1984, p. 43). Além disso, relembra que somos herdeiros de ideologias de classificação social (racial e sexual) das sociedades ibéricas -, considerando a formação histórica da Espanha e Portugal e a eterna disputa de território com os mouros e, também, uma organização de sociedade altamente hierarquizada - com diversas castas sociais e um violento controle social e político baseado em uma ideologia do branqueamento, transmitida e perpetuada pelos meios de comunicação e sistemas ideológicos tradicionais, reproduzindo o mito da superioridade branca.
} 
mulheres, gays, lésbicas, negros, índios, subdesenvolvidos, as economias emergentes, comunistas, terroristas, amarelos, etc. Todos estes serão incorporados na modernidade ou deixado de fora quando necessário. (MIGNOLO, 2012, p. 26)

Todo aquele que foge ao modelo moderno europeu de civilização, quando não incorporado ao seu discurso - como a ferida colonial de subordinação que ocorre com a falsa democracia racial brasileira -, é marginalizado, exteriorizado e subalternizado. 0 colonizador não apenas tenta incorporar os corpos "outros" no modelo moderno de civilização, mas também "inferiorizam seres humanos (colonialidade do ser), dominam o mundo natural (colonialidade da natureza), constroem hierarquias de gênero (colonialidade do gênero), hierarquizam lugares a partir de uma matriz de poder global com o objetivo de melhor explorá-los para a acumulação de capital” (RESTREPO; ROJAS, 2010, p. 37-38).

É a partir dessa imposição dicotômica hierárquica que se costuram as relações históricas: a mulher inferior diante do homem, o negro diante do branco, os corpos latinos diante do europeu, a tradição oral diante da escrita, os saberes e heranças ancestrais diante dos saberes da ciência, a homossexualidade diante da heterossexualidade etc. Os paradigmas de representação categorial eurocêntrica, assim chamados modernos, são ancorados na lógica dicotômica.

Segundo Maria Lugones, "a hierarquia entre seres humanos e não humanos é a dicotomia central da modernidade colonial” (LUGONES, 2019, p. 358), sendo ela uma ferramenta normativa de condenação utilizada pelos colonos para justificar atrocidades contra aqueles exteriorizados e marginalizados: "A desumanização que as torna aptas para a classificação, o processo de sujeitificação e a investida de tornar o/a colonizado/a menos que seres humanos. Isso contrasta fortemente com o processo de conversão que constitui a missão de cristianização" (LUGONES, 2019, p. 361).

A partir dessa lógica, "o homem europeu, burguês, colono, moderno foi transformado em sujeito/agente, próprio para governar, para a vida pública, um ser civilizado, heterossexual, cristão, um ser de mente e da razão" (LUGONES, 2019, p. 358) e sua mulher, "a mulher europeia burguesa não era entendida como um completo desse 
homem, e sim como alguém que reproduzia a humanidade e o capital por meio da sua pureza sexual, passividade e domesticidade" (LUGONES, 2019, p. 358).

A missão civilizatória do colonizador branco europeu, junto ao cristianismo, se concentrou na transformação do não humano colonizado em macho e fêmea, os corpos colonizados, julgados como deficientes do ponto de vista da civilização, os não brancos e não europeus, foram condenados como bestas, animalescos, grotescamente sexuais, pecaminosos e aberrações imperfeitas. Desse ponto de vista, "as pessoas colonizadas se tornaram machos e fêmeas; machos se tornaram não-humanos-como-não-homens, e fêmeas colonizadas se tornaram não-humanas-como-não-mulheres" (LUGONES, 2019, p. 359). A dualidade humano/não humano dá lugar ao dimorfismo sexual e este converteuse na base para a compreensão dicotômica dos gêneros como uma característica humana.

É importante lembrar como o capitalismo e o cristianismo foram aliados no processo de expansão "civilizatória"; o capitalista garantiu que o cristianismo se espalhasse pelo mundo e o cristianismo garantia ao capitalista a docilidade e civilização dos corpos através da missão evangelista cristã. O cristianismo teve um lugar fundamental na expansão do capitalismo, o que possibilitou as invasões e saques nas Américas. Assim como "a confissão cristã, o pecado e a divisão maniqueísta entre bem e mal serviam para marcar a sexualidade feminina como má” (LUGONES, 2019, p. 360), as fêmeas colonizadas eram relacionadas ao diabo, à sexualidade profana e impura.

Silvia Federici, em Calibã e a bruxa, descreve como o cristianismo modificou as relações de gênero em comunidades indígenas no Canadá: "A intervenção dos jesuítas franceses na disciplina e no treinamento dos Innu, no Canadá, nos dá um exemplo revelador de como se acumulavam as diferenças de gênero" (FEDERICI, 2017, p. 220-221). Segundo Federici, a invasão das Américas "poderia colocar em xeque todo conhecimento produzido até então na Europa - científico e religioso" (FEDERICI, 2017, p. 222) Para o europeu, foi melhor subjugar esse "novo mundo" e tudo o que dele haveria para contribuir em termos de conhecimentos, do que ter que rever suas teorias universais sobre as quais toda a sociedade europeia foi fundada. Ou seja, éramos uma ameaça, e isso explica a relação predatória com as Américas. 
A dicotomia hierárquica como marca da humanidade se tornou uma ferramenta normativa de condenação dos colonizados, de seus comportamentos e suas personalidades, o que Lugones chama de "alma" (LUGONES, 2019, p. 359) das pessoas colonizadas, dos subalternos, dos "índios", dos latinos, julgados como bestas selvagens. Essa é a forma mais perversa de opressão e dominação central do sistema moderno colonial; o apagamento dos saberes, memórias e das práticas que ali existiam.

Assim, à medida que o cristianismo se tornou o instrumento mais poderoso da missão de transformação, a normatividade que conectava os gêneros e a civilização passou a funcionar como uma forma de apagamento dos laços comunitários, das práticas ecológicas, do conhecimento sobre agricultura, da produção de utensílios, sobre o cosmos, e não apenas pela transformação e pelo controle sobre as práticas sexuais e produtivas. (LUGONES, 2019, p. 361)

A partir desse pressuposto, a mulher não branca é a mais incompleta e mais inferior de toda a hierarquia, pois ela não é nem mulher em relação à mulher branca, e também é inferior ao homem colonizado porque é fêmea e não macho. Essa é uma violência que, sistematicamente, as mulheres de cor sofrem: "mulheres não-brancas; mulheres vítimas da colonialidade do poder e, inseparavelmente, da colonialidade do gênero" (LUGONES, 2020, p. 53).

A partir das análises de Aníbal Quijano sobre a colonialidade do poder e da modernidade, Lugones constrói a noção de colonialidade de gênero. Segundo a socióloga feminista, “a análise de Quijano fornece-nos uma compreensão histórica da inseparabilidade da racialização e da exploração capitalista como constitutiva do sistema de poder capitalista que se ancorou na colonização das Américas" (LUGONES, 2019, p. 361). No entanto, o que Quijano não percebe é que mesmo o gênero, esse modelo de gênero universalista heteronormativo, é também um modelo moderno colonial capitalista, criado para dominação de outros povos. O binarismo de gênero faz parte de um projeto político e econômico; a colonialidade não incide apenas sobre o conceito de raça, mas também sobre o conceito de gênero, o que Lugones chama de "sistema de gênero moderno/colonial" (LUGONES, 2020, p. 56). 
Segundo Lugones, no padrão de Quijano "o gênero deve estar contido dentro da organização daquele 'âmbito básico da vida', que ele chama “"sexo, seus recursos e produtos'. [...] existe uma descrição de gênero que não é questionada, e que é demasiadamente estreita e hiperbiologizada" (LUGONES, 2020, p. 60). A conformidade de Quijano com o dimorfismo binário hetero-hegemônico faz parte da colonialidade de gênero que incide sobre as relações e que se organiza em torno da heterossexualidade e do patriarcado. Quijano não se contrapõe às hierarquias pré-estabelecidas a partir da dualidade moderna de macho/fêmea, homem/mulher que compõe a estrutura de família nuclear capitalista e, dessa forma, aceita um modelo eurocêntrico e global de gênero, mantendo velado o entendimento de que as mulheres colonizadas, as mulheres não brancas, foram não apenas subordinadas e destituídas de poder diante da racialização dos corpos, mas também subalternizadas diante das classificações normatizantes de gênero.

Quando problematizamos raça e gênero como embridadas nas opressões do poder colonial, conseguimos perceber como são violentos a heterossexualidade e o patriarcado nas sociedades resultantes do modelo de modernidade. Por isso, Lugones diz que "tanto o dimorfismo biológico, a dicotomia homem/mulher, a heterossexualidade e o patriarcado estão inscritos - com letras maiúsculas e hegemonicamente - no próprio significado de gênero" (LUGONES, 2020, p. 56), e somente pensando essas opressões juntas, é que podemos decolonizar as relações.

O colonizado feminino não foi somente racializado, como previa Quijano, mas também reinventado pela missão civilizatória como [mulher] por meio dos códigos de gênero ocidentais e que sacrificaram e marginalizaram corpos não brancos. O gênero é, portanto, não somente uma ferramenta da colonialidade, mas é propriamente um dos eixos da colonialidade/modernidade, que se traduz por colonialidade dos gêneros. Não considerar esse eixo como categoria de opressão colonial além do poder e saber, é ser conivente e reiterar mais uma opressão do sistema moderno/colonial. Entender gênero como um processo civilizatório moderno nos possibilita perceber as máscaras que carrega o projeto colonial: um sistema de gênero racializado, capitalista e heterossexual. 
Desse modo, colonialidade não se refere apenas à classificação e dominação racial, ela é um fenômeno mais amplo, ela é "um dos eixos do sistema de poder e, como tal, atravessa o controle do acesso ao sexo, a autoridade coletiva, o trabalho e a subjetividade/intersubjetividade, e atravessa também a produção de conhecimento a partir do próprio interior dessas relações intersubjetivas" (LUGONES, 2020, p. 57). Toda forma de controle dos sexos, todo padrão de gênero, da subjetividade do que entendemos como homem e mulher, da ocupação dos seus trabalhos, das práticas cotidianas e das tarefas que desempenham, e a manutenção das imagens sobre o masculino/feminino, são reflexos de um sistema moderno colonial de gênero, um domínio particular da vida humana.

A transformação civilizatória trouxe com ela a colonização também da memória, do entendimento das pessoas sobre si mesmas e de suas relações intersubjetivas, o que resultou num grande afastamento das relações com os povos originários, das práticas que se mantinham, das concepções de mundo, dos cuidados com a terra e seu consumo, bem como a concepção de realidade e organização social. "A imposição colonial dos gêneros atravessa questões ecológicas, econômicas, governamentais, atravessa relações com o mundo dos espíritos, o conhecimento, bem como as práticas diárias que nos ensinam ou a cuidar do mundo ou a destruí-Io" (LUGONES, 2019, p. 357).

Por isso é preciso incluir um "reaprender" através de um olhar decolonial, um feminismo não apenas como um movimento que luta sobre as opressões das mulheres, mas que vai além das suas opressões, entendendo as situações em que vivem, os efeitos da racialização, da colonização, da exploração capitalista e das imposições da heterossexualidade, das noções de consumo, dos lugares de privilégios etc. "Decolonizar os gêneros é necessariamente uma práxis" (LUGONES, 2019, p. 363), um devir, não marcado pelas hegemonias das categorias que esgotam as possibilidades de agenciamentos, mas trata-se de uma transformação crítica que se faz pela prática do diaa-dia, da experiência, uma "intersubjetividade historicizada e encarnada" (LUGONES, 2019, p. 363). 


\section{Um pensamento feminista para além das categorias}

Na medida em que a colonialidade se infiltra em todas os aspectos da vida, existe uma multiplicidade de corpos cujas relações com o mundo não seguem necessariamente o modelo colonial. Lugones chama esse processo de "lócus fraturado" (LUGONES, 2019, p. 372), no qual todo processo de violência colonial é um processo em que há opressão, mas também resistências que fraturam esse lócus e revelam subjetividades ativas, um movimento que sucede em outras formas criativas de pensar, de se relacionar, "que são antitéticas à lógica do capital” (LUGONES, 2019, p. 372), considerando ser esse um começo para uma decolonialidade, que tem ênfase nas coalizões possíveis a partir da diferença colonial.

Dessa forma, a sujeição dos corpos às categorias como marcadores é prejudicial ao movimento feminista, porque nenhum corpo é categorizante, possível de ser enquadrado por classificações hegemônicas, todo corpo é sempre outro, nunca o é sozinho e está sempre marcado de múltiplas experiências. Quando pensamos corpos por categorias, estamos diretamente invisibilizando e silenciando outras formas de existências. Por exemplo, a categoria mulher invisibiliza a noção de mulher trans, negra, latina, indígena, camponesa, asiática, hislâmica, chicana etc. Isso porque o termo "mulher" em si mesmo, sem especificidades, não tem sentido, ou tem um sentido racista, já que a lógica categorial, historicamente, seleciona como mulher somente o grupo dominante: mulheres burguesas brancas heterossexuais. As mulheres não brancas, fogem às categorias universais, suas práticas e saberes não são cristalizados nas dicotomias hierárquicas da modernidade colonial. Por isso, Lugones ressalta que "a intersecção de raça, classe, sexualidade e gênero extrapola as categorias da modernidade" (LUGONES, 2019, p. 357).

"Se mulher e negro são categorias homogêneas, atômicas, separáveis, sua intersecção nos mostra a falta de mulheres negras" (LUGONES, 2019, p. 357). Isso porque na intersecção entre "mulher" e "negro" há uma ausência, a mulher negra, precisamente, porque nem mulher nem negro a incluem. "A intersecção nos mostra um vazio. Por isso uma vez que a interseccionalidade nos mostra o que se perde, ficamos com a tarefa de 
reconceitualizar a lógica da intersecção, para, desse modo, evitar a separação das categorias existentes e o pensamento categorial” (LUGONES, 2020, p. 60). Somente quando percebermos gênero e raça como tramados e fundidos indissoluvelmente, poderemos realmente ver as mulheres de cor.

A partir do pensamento categórico universalista, o subalterno não passa de oprimido. O camponês, indígena, mulher negra, corpos trans, serão sempre vistos como grupos condenados e vitimizados. No entanto, esses grupos e essas comunidades, tanto em grandes centros urbanos, como em comunidades de povos originários, "nunca aceitaram a invasão colonial passivamente" (LUGONES, 2020, p. 53), são corpos de resistência. Assim, se quisermos pensar em um feminismo radicalmente decolonial, é preciso que nos libertemos das amarras das categorias e pensemos a partir de uma “infrapolítica” (LUGONES, 2019, p. 363), que nasce da diferença colonial, da multiplicidade dos corpos resistentes; uma política que não está inscrita nas cadeiras públicas, mas a partir de agências da resistência, marcada por "um olhar para dentro", na organização social, da "esfera subjetiva-intersubjetiva" (LUGONES, 2019, p. 364), na autodefinição das nossas existências, atribuídas de n-gêneros, de corpos não hegemônicos, não binários, não categorizantes. Esse é "o senso mínimo de agência necessário para que a relação oprimir - resistir seja ativa, sem recorrer ao senso máximo de agência da subjetividade moderna" (LUGONES, 2019, p. 363).

Esse é um feminismo que acredita na potência coletiva, na dimensão da cultura oral, nos espaços de resistências, como a arte grafiteira das periferias, grupos folclóricos de atuação política, como Mulheres ao vento, da favela da Maré; a organização das mães nas favelas que reivindicam o direito e a segurança de seus filhos; nos coletivos como Mães de maio, que reagem contra a violência policial do Estado; assim como as cantoras de blues nos Estados Unidos nos anos 60, citadas por Hill Collins; o funk das favelas do Rio de Janeiro, que retratam seu cotidiano e a ameaça à vida dos favelados; as escritoras e acadêmicas negras que estão diariamente lutando contra um racismo epistemológico; grupos de resistência como Slam das minas e Queerlombo, com suas poesia e performances pretas LGBTQIA+ pelas ruas, lutando contra a heteronormatividade e o 
racismo... todos são afirmações e práticas que produzem suas próprias estruturas de resistência coletivas e que muitas vezes não estão inscritas na agenda universal feminista.

É a partir de um feminismo da experiência, que afirma a potência da vida cotidiana, que acredito ser possível criar novas narrativas, novas histórias, um outro modo de enxergar o mundo e xs outrxs, a terra, o corpo, a espiritualidade e mesmo a relação com a morte. Lembrando que "ninguém resiste à colonialidade dos gêneros sozinho" (LUGONES, 2019, p. 372), somente é possível resistir a ela com uma vivência que é compartilhada e que consegue entender as próprias ações, garantindo certo reconhecimento com o outro. Um movimento que é individual e sozinho não pode ser decolonial, pois "as comunidades, e não os indivíduos, possibilitam o fazer; as pessoas produzem junto de outras, nunca em isolamento" (LUGONES, 2019, p. 372). Mesmo o autoconhecimento é um resultado das coalizões entre grupos e dos agenciamentos entre comunidades, "o boca a boca, a passagem de mão em mão das práticas vividas, dos valores, crenças ontológicas, espaços-tempo e cosmologias constituem as pessoas." (LUGONES, 2019, p. 372).

A produção da vida diária, na qual existimos, produze nossos "Eus", "à medida que nos provêm vestimentas, comida, economias e ecologias, gestos, ritmos, habitats, e noções de espaço e tempo; todos produtos significativos para nós" (LUGONES, 2019, p. 373). Esses saberes e/ou práticas, que nos são negados pelo colonizador, "afirmam um ideal da vida acima do lucro, de um comunalismo acima do individualismo, de um 'estar' em vez do empreendimento; seres em relação em vez de separados dicotomicamente repetidas vezes em fragmentos hierárquica e violentamente ordenados" (LUGONES, 2019, p. 373). Essas formas de ser e de dar valor são parte da resposta a resistência à colonialidade. Resistir e recriar, não descolonizar num sentido de deixar de existir, mas de responder a um sistema opressor colonial de forma a decolonizar a vida e a experiência.

Lugones está, dessa forma, pensando no entrelaçamento da vida individual com o coletivo, pessoas que não necessariamente estão assumindo papéis representativos, oficiais, ou governamentais, mas assumindo um comunalismo, acreditando ser esse o caminho para a decolonialidade. Lugones chama essa proposta de uma "ética da coalizão" (LUGONES, 2019, p. 373), um "ser-sendo relacional que estende e interconecta 
seu solo povoado" (LUGONES, 2019, p. 373), assim, pensando o "eu relacional como uma proposta à colonialidade dos gêneros na diferença colonial” (LUGONES, 2019, p. 373). A resistência se faz nas coalizões no dia-a-dia, a partir das questões diárias vividas na tensão das feridas coloniais: "A lógica da coalizão desafia a das dicotomias; as diferenças nunca são vistas em relação às dicotomias, mas a lógica tem como oposição a lógica do poder. A multiplicidade nunca é reduzida" (LUGONES, 2019, p. 373).

Acredito que Lugones não está apontando apenas para repensarmos as categorias, criando outras categorias ou categorias mais alargadas, mas está nos alertando que o pensamento por categorias ja é propriamente um pensar colonial e moderno, não havendo categoria de gênero, por exemplo, que salte para fora do modelo moderno colonial, sendo esta uma forma de conjunto, de nomeação estrutural. "As categorias são entendidas como homogêneas e que elas selecionam um dominante, em seu grupo, como norma" (LUGONES, 2020, p. 60).

Para Lugones, “o Eu relacional não está no repensar da relação com o opressor no ponto de vista do oprimido, e sim no aprofundamento da lógica da diferença e da multiplicidade e da coalizão" (LUGONES, 2019, p. 373). A ênfase está em manter a multiplicidade e não na reformulação de mais categorias e identidades, isso seria para ela a “manutenção de um 'produto' híbrido” (LUGONES, 2019, p. 373), ainda que pensar as categorias de forma expandida e revisada fosse uma forma de saída para as feministas pós-modernas e pós-estruturalistas, esse método ainda esconde a diferença colonial.

O reparo dessas categorias seria também um pensamento moderno, no qual a política baseada nas identidades é um modelo moderno de saber. Lugones propõe uma transcendência do discurso colonial moderno, negando uma política da inclusão, de trazer para dentro, da reformulação e emancipação do subalterno, isso para ela não resolveria o problema; Mas é preciso romper com esse pensamento colonial. Visto que o processo de emancipação é um processo de inclusão ao discurso moderno colonial, isso pouco seria um pensamento decolonial que rompe com a lógica colonial. Esse pensamento inclusivo é justamente uma visão “erótica social” (LUGONES, 2019, p. 373), que apenas minimizaria as opressões coloniais. Lugones propõe "uma forma de pensar uma possibilidade de coalizão que leva em consideração a lógica da decolonialidade" 
(LUGONES, 2019, p. 373), uma consciência que transcende a colonialidade e "assume as diferenças que tornam o ser-sendo criativo, que permite encenações totalmente desafiadoras da lógica das dicotomias" (LUGONES, 2019, p. 373) ou seja, o pensamento de Lugones tem como partida a retomada da Abya Yala para a transformação social e política.

Isso é o que a autora chama de “virada decolonial” (LUGONES, 2019, p. 373), uma mudança metodológica de pensar o feminismo e suas interseccionalidades, um método que pressupõe como partida um salto para fora das estruturas dicotômicas, das categorias e das unidades marcadoras, mas que estabelece uma proposta de coalizão entre as multiplicidades. Isso não quer dizer que as categorias deixaram de existir, que serão apagadas, uma vez que colonizado não é possível descolonizar, mas é rejeitando a oferta colonial que categoriza os corpos que podemos pensar em um movimento feminista mais rebelde e desobediente a essas estruturas.

O giro decolonial e o feminismo antirracista reforçam um feminismo para fora das categorias universais, apontando para coalizões entre diferentes, mas sempre abertas, inacabadas. Mas entendendo que, mesmo o sujeito do feminino como mulher é desconstruído a partir das reflexões feitas sobre as intersecções de raça e gênero, em que não existe sujeito deslocado de suas referências, suas origens, suas experiências de classe, raça, gênero, sexualidade, território etc. Cada corpo se define não por uma essência particular, mas por suas diferentes experiências encarnadas.

A partir de um pensamento latino-americano decolonial, Yuderkys Espinosa Miñoso afirma: "existe uma memória corporal e visual que acompanha os discursos, sensações de alegria, de dor, de vitória ou derrota, de expectativas, incredulidades ou certezas" (MIÑOSO, 2020, p. 105). A filósofa chama esse saber de "genealogia da experiência do feminino na América Latina" (MIÑOSO, 2020, p. 105), que se utiliza da própria experiência como documento substancial, localizada nas práticas vivenciadas e que possibilita desvendar criticamente a produção da própria ideia de latino-americano, formulada pelo colono. A partir de uma genealogia da experiência, talvez seja possível pensar em coalizões como um sistema de significações que não se fecha nunca, pois se isso ocorresse, encerraria o jogo das diferenças. Essas coalizões, não essenciais e 
individualistas, são possibilidades de relações com o outro, não independentes umas das outras. Não existem, portanto, sujeitos que não sejam relacionais, pois cada corpo está em uma relação diferencial com xs outrxs, não em uma relação antagônica uma com o outra, mas comunilista.

Abrir mão das categorias de unidades universais não significa abrir mão dos corpos produzidos por suas experiências, abolindo gênero, raça, sexualidade; mas significa fugir das categorias forjadas pelo regime moderno colonial capitalista e de suas fronteiras. Pois, como seria pensar a luta anti-heteronormativa sem os corpos lésbicos, trans, não binários? Não seria esaa uma luta anti-heteronormativa se não houvesse os corpos que confrontam as imagens e os modelos universais. Assim, dizer-se não categórico não é abrir mão das particularidades dos corpos e suas performatividades da experiência. Assim como a autodeclaração de um feminismo não universalista, não quer dizer que não seja possível que se construam agencias e coalizões que compartilham das mesmas lutas e opressões.

Efectivamente sería absurdo pensar que esa agencia puede prescindir del sujeto oprimido por el sistema moderno colonial de género. $Y$ es por eso mismo que la idea de un feminismo sin mujeres, como lo proponía un grupo que se denomina "posfeminista" en Chile, es más que descabellada; como descabellado sería pensar una política antirracista sin la presencia y la preponderancia de los cuerpos sistemáticamente violentados por el sistema colonial capitalista, es decir, los cuerpos producidos e identificados como negros-indígenas-bárbaros; como descabellado sería pensar una lucha contra el régimen heterosexual que prescindiera de los cuerpos lesbianos, trans o en rebelión contra ese régimen. (MIÑOSO, 2013, p. 163)

Também não seria possível pensar num sujeito da opressão e num sujeito oprimido separadamente, pois existem micro-opressões e múltiplas formas de opressões e privilégios embridadas. Um corpo que é oprimido pode ocupar um lugar também de privilégio dependendo do local em que vive, do pertencimento econômico e de classe, se é hétero ou homoafetivo etc. Mais uma vez, se torna problemático o pensar a partir de categorias porque estas estabelecem recortes entre um e outro, entre o que é oprimido e 
o que é opressor, entre o privilegiado e o subalterno, um pensamento sempre antagônico. Mas do que isso, constroem uma ideia dualista de que estes não podem coexistir juntos.

Construir um pensamento a partir de categorias significaria continuar apegado a uma compreensão universalista e totalizante do sujeito, como sujeitos sempre em oposições de subalternos e de opressores. A partir desse modelo, seguiremos reproduzindo a ideia de que, para lutar contra um regime, é preciso ser o sujeito produzido e sustentado por esse regime de opressões, o que seria uma perda para as possíveis coalizões políticas. "Esta forma de construcción de la unidad política en base a que sólo puede actuarla quien está en posición de opresión es imposible de conciliar con la convicción que sostenemos las feministas descoloniales de que la opresión opera coconstitutiva e interdependientemente" (MIÑOSO, 2013, p. 164).

Um pensamento que se propõe anti-categorial é um projeto político que reconhece a dívida histórica com os grupos subalternizados e que também reconhece privilégios e opressões interligadas. Um sujeito branco mestiço burguês, seja latinoamericano, europeu ou norte-americano, pode reconhecer-se como um corpo marcado por privilégios e estar junto trabalhando para construir um movimento feminista antirracista e que possibilite desfazer seu próprio lugar de poder. Assim como os homens racializados não podem continuar a adiar a reflexão sobre como a colonialidade de gênero produziu lugares de privilégio para o homem racializado dentro de suas próprias comunidades, na medida em que reproduzem padrões brancos. Dessa forma, também podemos pensar sobre os privilégios da heterossexualidade diante das violências sofridas pelos corpxs LGBTQIA+. As intersecções de opressões e privilégios não se fazem por oposição e não são hierárquicas, mas estão mergulhadas num modelo moderno colonial que sustenta as mesmas. Assim afirma Yuderkys:

mujeres, varones, trans, travestis, lesbianas podrían estar trabajando también por un proyecto feminista antirracista y descolonial, haciendo un trabajo contra su propio privilegio (en el caso del varón, como varón; en el caso de la mujer o la trans blanca-burguesa, como blanca- burguesa...). (MIÑOSO, 2013, p. 163) 
O feminismo decolonial se constitui como um movimento internacionalista e nunca um feminismo de amplitude global e universal, mas que traz questões que se multiplicam, como a de que um corpo nunca é definido por categorias e unidades universais, mas é relacional com todas as esferas da sociedade vigente, dos grupos em questão, e que sobretudo, respeitando as demandas das comunidades e dos coletivos, é ele um projeto em aberto. Um feminismo que acredita que certa ênfase deve ser dada à metodologia do pensar, como resistência às colonialidades, sejam elas de gênero, do ser, do saber, do poder e suas interseccionalidades de raça, classe, território, cultura, sexualidade etc. Não sendo possível reconstruir um movimento anterior, só é possível mover-se para frente, criando um outro movimento. "Se trata de explicitar lo que a nuestro entender constituye un punto de inflexión, una bifurcación en el camino que hemos venido recorriend" (MIÑOSO, 2013, p. 144). Essa é a transição que estamos experienciando com o feminismo decolonial, feminismo subalterno, contra-hegemônico e radicalmente assentado sobre a geopoliticamente Abya Yala.

Dessa forma, a responsabilidade do feminismo decolonial é colocada por Lugones: "Como aprendemos uns sobre os outros? Como fazemos isso sem machucar uns aos outros, mas com a coragem de acolher os entrelaçamentos da vida diária que podem até revelar certas traições? Como cruzamos fronteiras sem nos tornarmos conquistadores?" (LUGONES, 2019, p. 373). Um feminismo que se preocupa em enxergar a vida cotidiana como um processo de luta e resistência, que vê a mulher latina, não branca, “amerifricana” (GONZALEZ, 1984, p. 9), camponesa, fora do lugar de vítimas, mas que reconhece suas multiplicidades. Um feminismo que enxerga que, nas diferenças, podemos fazer coalizões poderosas.

\section{Considerações finais}

Está na hora de percebermos que a teoria é prática, que faz parte de nossas próprias vidas, de como consumimos as coisas, de como gastamos nosso tempo, de como cultivamos as relações afetivas, de como enxergamos o mundo, xs outrxs, a pluralidade 
dos corpos, suas sexualidades etc. Nosso feminismo é sobre mulheres indígenas, mulheres latinas, mulheres negras e mestiças. Na medida em que o capitalismo privatiza a vida, que a desigualdade é determinada pelo tom da pele, que a violência é relativizada de acordo com a sexualidade e gênero daquele corpo, a reconstrução das nossas vidas requer primeiro uma transformação profunda das nossas práticas diárias, assim como a produção de bens comuns passa a ser uma necessidade: a decolonização da vida, do trabalho, da produção, assim como também a formação de novas coalizões de resistência. Nosso feminismo é necessariamente anticapitalista, antirracista e antiimperialista.

Dentre as potentes frases de Lugones destaco esta: "estamos nos movendo em um tempo de encruzilhadas, de enxergarmos umas às outras na diferença colonial construindo um novo sujeito de uma nova geopolítica feminista de saber e amar" (LUGONES, 2019, p. 373). Lembrando que encruzilhadas, o cruzamento de ruas, são lugares onde são feitas oferendas a Exu e Pombagira, entidades espirituais que abrem caminhos e são mensageiras. Assim também podemos pensar que Lugones nos deixou uma chamada para construir novos caminhos, novos imaginários e novas práticas a partir de um outro lugar, desterritorializando o pensamento, partindo da diferença colonial, da multiplicidade dos corpos e suas comunidades.

A encruzilhada é também o marco de um lugar e aqui penso em um outro sujeito, o subalterno que se inscreve como potência decolonial, sendo ele o fora do discurso ocidental, que possibilita um feminismo de fuga de um sistema opressor, um feminismo da experiência, do cotidiano, que possibilite coalizões nas favelas, nas comunidades que ainda resistem ao modelo capitalista moderno colonial, nas agências micro, pois sempre existe resistência, mesmo que mínima. Hoje nos encontramos diante de um chamado, ou mesmo de uma necessidade de existência: Mulheres subalternizadas, marginalizadas, nossas irmãs latinas, amerifricanas, ameríndias, está na hora de criarmos alternativas comunitárias, do bem viver, ou mesmo resgatando práticas de cuidado que já existiram antes da implementação brutal do capitalismo, resgatando, portanto, nossa ancestralidade amerifricana. 


\section{Referências}

ABYA YALA. In: Enciclopédia Latino Americana. Por Carlos Walter Porto-Gonçalves. São Paulo: Boitempo, 2019. Disponível em: http://latinoamericana.wiki.br/verbetes/a/abyayala. Acesso em: 26/08/2020.

BALLESTRIN, Luciana. América Latina e o giro decolonial. Revista Brasileira de Ciência Política, Brasília, n.11, maio/ago. 2013.

CUSICANQUI, Silvia Rivera. Un mundo ch'ixi es posible: ensayos desde un presente en crisis. Buenos Aires: Tinta Limón, 2018.

FEDERICI, Silvia. Calibã e a bruxa: mulheres, corpo e acumulação primitiva. São Paulo: Elefante, 2017.

GONZALEZ, Lélia. Racismo e sexismo na cultura brasileira. Revista Ciências Sociais Hoje, São Paulo: Anpocs, p. 223-244, 1984.

GONZALEZ, Lélia. Por um feminismo afro-latino-americano. In: HOLLANDA, Heloisa Buarque de (org.). Pensamento feminista hoje: perspectivas decoloniais. Rio de Janeiro: Bazar do Tempo, 2020.

KILOMBA, Grada. Memórias da plantação: episódios de racismo cotidiano. Rio de Janeiro: Cobogó, 2019.

LUGONES, Maria. Colonialidade e gênero. In: HOLLANDA, Heloisa Buarque de (org.). Pensamento feminista hoje: perspectivas decoloniais. Rio de Janeiro: Bazar do tempo, 2020. p. 53-83.

LUGONES, Maria. Rumo a um feminismo decolonial. In: HOLLANDA, Heloisa Buarque de (org.). Pensamento feminista: conceitos fundamentais. Rio de Janeiro: Bazar do tempo, 2019. p. 357-377.

MIGNOLO, Walter. Decolonizing western epistemology/building decolonial epistemologies. In: ISASI-DÍAZ, Ada María; MENDIETA, Eduardo (eds.). Decolonizing epistemologies: Latina/o theology and philosophy. New York: Fordham University Press, 2012. p. 19-43.

MIÑOSO, Yuderkys Espinosa. El ideal de mujer del feminismo implica la explotación de la mayoria de mujeres y varones extraeuropeos. [Entrevista cedida a] Amanda Andrade. GLEFAS, Colombia, n.1, jun./agos. 2020. Disponível em: http://glefas.org/entrevista-elideal-de-mujer-del-feminismo-implica-la-explotacion-de-la-mayoria-de-mujeres-y-varonesextraeuropeos/. Acesso em: 22/04/2020. 
MIÑOSO, Yuderkys Espinosa. Fazendo uma genealogia da experiência: o método rumo a uma crítica da colonialidade da razão feminista a partir da experiência histórica na América Latina. In: HOLLANDA, Heloisa Buarque de (org.). Pensamento feminista hoje: perspectivas decoloniais. Rio de Janeiro: Bazar do tempo, 2020. p. 97-118.

MIÑOSO, Yuderkys Espinosa. Y la una no se mueve sin la otra: descolonialidad, antiracismo y feminismo. una trieja inseparable para los procesos de cambio. Revista Venezolana de Estudios de la mujer, Venezuela, vol. 21/n46, p. 47-64, Jan - JUN. 2013.

QUIJANO, Aníbal. Colonialidad del poder, globalización y democracia. Revista de Ciencias Sociales de la Universidad Autónoma de Nuevo León, Buenos Aires, ano 17, n. 37, p. 4378, maio. 2001.

RESTREPO, Eduardo; ROJAS, Axel. Inflexión decolonial: fuentes, conceptos y cuestionamientos. Popayán: Editorial Universidad del Cauca, 2010.

OYĚWÙMÍ, Oyèrónkẹ. DESAPRENDENDO LIÇÕES DA COLONIALIDADE: ESCAVANDO SABERES SUBJUGADOS E EPISTEMOLOGIAS MARGINALIZADAS. Por Decolonialidade e perspectiva negra. 2019. 1 vídeo (12 min). Disponível em: https://www.youtube.com/watch?v=zeFlgvTI8ZU. Acesso em 29/05/2020. 